\title{
Ice thinning, upstream advection, and non-climatic biases for the upper $89 \%$ of the EDML ice core from a nested model of the Antarctic ice sheet
}

\author{
P. Huybrechts ${ }^{1,2}$, O. Rybak ${ }^{2,3}$, F. Pattyn ${ }^{4}$, U. Ruth ${ }^{2}$, and D. Steinhage ${ }^{2}$ \\ ${ }^{1}$ Departement Geografie, Vrije Universiteit Brussel, Pleinlaan 2, 1050 Brussel, Belgium \\ ${ }^{2}$ Alfred-Wegener-Institut für Polar- und Meeresforschung, Postfach 120161, 27515 Bremerhaven, Germany \\ ${ }^{3}$ Scientific Research Centre, Russian Academy of Sciences, Teatralnaya 8-a, 354000 Sochi, Russia \\ ${ }^{4}$ Laboratoire de Glaciologie Polaire, Département des Sciences de la Terre et de l'Environnement (DSTE), Université Libre \\ de Bruxelles, CP160/03, Av. F. Roosevelt 50, 1050 Bruxelles, Belgium
}

Received: 3 April 2007 - Published in Clim. Past Discuss.: 7 May 2007

Revised: 3 September 2007 - Accepted: 11 September 2007 - Published: 2 October 2007

\begin{abstract}
A nested ice flow model was developed for eastern Dronning Maud Land to assist with the dating and interpretation of the EDML deep ice core. The model consists of a high-resolution higher-order ice dynamic flow model that was nested into a comprehensive 3-D thermomechanical model of the whole Antarctic ice sheet. As the drill site is on a flank position the calculations specifically take into account the effects of horizontal advection as deeper ice in the core originated from higher inland. First the regional velocity field and ice sheet geometry is obtained from a forward experiment over the last 8 glacial cycles. The result is subsequently employed in a Lagrangian backtracing algorithm to provide particle paths back to their time and place of deposition. The procedure directly yields the depth-age distribution, surface conditions at particle origin, and a suite of relevant parameters such as initial annual layer thickness. This paper discusses the method and the main results of the experiment, including the ice core chronology, the non-climatic corrections needed to extract the climatic part of the signal, and the thinning function. The focus is on the upper $89 \%$ of the ice core (appr. 170 kyears) as the dating below that is increasingly less robust owing to the unknown value of the geothermal heat flux. It is found that the temperature biases resulting from variations of surface elevation are up to half of the magnitude of the climatic changes themselves.
\end{abstract}

Correspondence to: P. Huybrechts

(phuybrec@vub.ac.be)

\section{Introduction}

Physical and chemical properties of Antarctic ice cores contain information on past changes of climatic variables such as temperature, atmospheric gas composition, and biogeochemical aerosol fluxes reaching back several hundred thousands of years in time. Relevant proxy data have been obtained from long ice cores drilled at the Vostok, Dome Fuji, Dome C, and Kohnen stations (Petit et al., 1999; Watanabe et al., 2003; EPICA community members, 2004, 2006). Drilling of the latter two cores was carried out within the framework of the European Project for Ice Coring in Antarctica (EPICA).

The EDML (EPICA Dronning Maud Land) ice core acquired at Kohnen station $\left(75^{\circ} 00.104^{\prime} \mathrm{S}, 0^{\circ} 04.07^{\prime} \mathrm{E}\right)$ was drilled between 2001 and 2006 for a total depth of $2774 \mathrm{~m}$ down to the bedrock (EPICA community members, 2006). At this site, the annual accumulation rate is $64 \mathrm{~kg} \mathrm{~m}^{-2} \mathrm{yr}^{-1}$ (7.0 $\mathrm{cm} \mathrm{yr}^{-1}$ of ice equivalent, Oerter et al., 2000) allowing for a higher-resolution climatic record of the last glacial period compared to other drilling sites on the East Antarctic plateau. A correct interpretation of the ice core record requires that two basic problems are adequately solved. First of all, the key problem of any climate reconstruction not only from ice core proxies is accurate dating. Annual layers can be visually counted in the EDML core back to the last glacial-interglacial transition. Below this horizon it is necessary to apply indirect methods, including correlation of noticeable events like volcanic eruptions or extreme climatic events, which are well-dated independently, and modeling. EDML1, the official time scale for the EDML ice core, did not rely on layer counting or direct modeling. Instead, EDML1 was interlinked with EDC3, the new chronology for the EPICA ice core from Dome C through stratigraphic matching of 322 volcanic events over the last $128 \mathrm{ka}$. The

Published by Copernicus Publications on behalf of the European Geosciences Union. 
EDC3 time scale was in turn obtained from glaciological modeling at Dome $\mathrm{C}$ constrained by well-dated age control points for both cores transferred using the tight stratigraphic link (EPICA community members, 2004, 2006; Ruth et al., 2007; Severi et al., 2007; Parrenin et al., 2007).

The second problem which needs to be addressed results from the dynamics of the Antarctic ice sheet over the time period covered by the ice core. Most importantly, the surface elevation at the time of deposition of the ice has varied under the influence of changes in accumulation rate, ice temperature, the position of the grounding line, horizontal ice flow, and possibly other factors (Huybrechts, 2002). These elevation changes cause non-climatic biases in the temperature records retrieved from the ice cores. The long isotope records from Dome Fuji and Dome $\mathrm{C}$ were acquired from relatively stable ice domes with little or no horizontal movement that probably underwent vertical glacial-interglacial elevation changes of the order of 100-200 m (Huybrechts, 2002). With a typical surface temperature lapse rate on the Antarctic plateau of $-0.014^{\circ} \mathrm{C} \mathrm{m}^{-1}$ (Fortuin and Oerlemans, 1990), this corresponds to biases of the order of $2-3^{\circ} \mathrm{C}$, or about $25 \%$ of the inferred glacial-interglacial temperature shift. Kohnen station, however, differs from these latter locations as it is not situated on a dome. Instead, it is located along the axis of a gently sloping ridge near to a saddle point about $80 \mathrm{~km}$ further downslope. In the upstream direction, the ice divide can be traced for about $1280 \mathrm{~km}$ up to Dome Fuji. Because of its flank position, deeper ice at Kohnen was deposited further inland at a progressively higher elevation. This causes an additional non-climatic bias, the strength of which depends on the magnitude of the horizontal velocity and the upstream slope of the ice sheet. For a typical upstream flow velocity of $1 \mathrm{~m} \mathrm{yr}^{-1}$ and an upstream surface gradient of $1.7 \times 10^{-3}$ this corresponds to an additional bias of about $2.5^{\circ} \mathrm{C}$ per 100000 years, which systematic contribution is equally non-negligible compared to the climate signal itself.

Our approach to obtaining the chronology and nonclimatic biases is to accurately model the ice sheet history and its flow dynamics for the full time span covered by the ice core. This is done over the entire region where ice particles ending up at Kohnen are believed to have originated. We nested a high-resolution higher-order ice dynamic model, hereafter called FSM (Pattyn, 2003), within a threedimensional thermomechanically whole Antarctic ice sheet model, hereafter called LSM (Huybrechts, 2002). The reconstructed high-resolution velocity field from a forward experiment with the nested model was subsequently used in a Lagrangian backtracing algorithm to establish the trajectories of ice particles back to their respective places of deposition. The latter information can be directly linked to a wealth of spatio-temporal parameters required for a correct interpretation of the ice core. The procedure fully accounts for time-dependent changes in such crucial parameters as ice thickness, flow direction, flow velocity, accumulation rate, and basal melting rates. In contrast to the earlier model study of Savvin et al. (2000) with SICOPOLIS, our model has a much higher resolution as allowed for by detailed observational data from the various EDML pre-site surveys. The nested FSM furthermore includes longitudinal and horizontal shear stress gradients in the stress balance, and use was made of Lagrangian backward tracing from the known location of the ice core site.

The time period under consideration is limited to approximately the last $170 \mathrm{kyr}$. This time span corresponds to the upper $89 \%$ or $2477 \mathrm{~m}$ of the ice core. It covers all of the last glacial cycle and the previous interglacial, and a significant fraction of the penultimate glacial period. The interpretation of the deepest layers increasingly depends on the unknown value of the geothermal heat flux, and the associated rate of basal melting, and was therefore excluded from the present analysis. The models and the Lagrangian backtracing method are explained in Sects. 2 and 3. It is followed by a discussion of the ice core chronology, the non-climatic biases, and the thinning function in Sects. 4 and 5. Conclusions are summarized in Sect. 6.

\section{The nested ice sheet model for the forward experi- ment}

The nested ice sheet model has two components. The Large Scale Model covers all of the Antarctic ice sheet and is run on a $20 \mathrm{~km}$ horizontal resolution grid with 30 layers in the vertical. It provides boundary conditions for the Fine Scale Model which is implemented over an area of $600 \mathrm{~km} \times 400 \mathrm{~km}$ in eastern Dronning Maud Land. The FSM grid has a $2.5 \mathrm{~km}$ horizontal resolution with 101 equally-spaced layers in the vertical and comprises all of the area where Kohnen ice particles are believed to have originated. All prognostic calculations (ice thickness, bed elevation, ice temperature) take place in the LSM. The main output of the FSM is the diagnostic three-dimensional velocity field in the nested domain as a function of time. All model parameters employed in FSM correspond to those defined in LSM. The only difference between LSM and FSM concerns the approximations made in the force balance to calculate the horizontal velocity components. Figure 1 shows the respective domains over which both the LSM and FSM are implemented.

\subsection{The large scale model LSM}

The LSM is a fully-fledged 3-D thermomechanically coupled ice sheet/ice-shelf/lithosphere model implemented on a mesh of $281 \times 281$ horizontal gridpoints. It is fully described in Huybrechts and de Wolde (1999) and Huybrechts (2002) to which the interested reader is referred. Grounded ice flow results from both internal ice deformation and basal sliding according to the usual assumptions made within the shallow-ice approximation (SIA), that is, only shearing in 
horizontal planes is considered. Longitudinal stress gradients in the flow direction and shear stress gradients perpendicular to the flow are ignored owing to the small height-to-width aspect ratio (Hutter, 1983). LSM accounts for groundingline migration through explicit modeling of ice shelf flow and a stress transition zone across the grounding line in combination with a floatation criterion. The model is driven by prescribed changes of sea level, surface temperature, surface mass balance and melting below the ice shelves. The enhancement factor in Glen's flow law has been slightly readjusted from the earlier value of 2 to a new value of 1.2 to optimally represent the observed ice thickness in eastern Dronning Maud Land in a time dependent run covering the last 8 glacial cycles. In this way, the modeled surface elevation in LSM differs by less than $50 \mathrm{~m}$ from the observations over the whole area covered by the FSM domain. Apart from this slight retuning, all other formulations and model parameters are identical to those given in Huybrechts and de Wolde (1999) and Huybrechts (2002), and are therefore not repeated again. The standard geothermal heat flux of $54.6 \mathrm{~m} \mathrm{~W} \mathrm{~m}^{-2}$ is applied at the lower boundary of a $4 \mathrm{~km}$ thick bedrock slab underlying the ice sheet. The time step for the numerical integration of the continuity equation is 1 year, but larger for numerically more stable quantities such as ice temperature, ice age, and bedrock height.

\subsection{The fine scale model FSM}

The FSM is a so-called higher-order model as it includes both longitudinal and transverse stress gradients in the force balance equations (Pattyn, 2003). These additional terms improve the velocity solution at ice divides, near to the ice-sheet margin, and in areas with pronounced relief or high velocity gradients. They are also required for a more realistic solution on numerical grids where the horizontal resolution is of the order of the ice thickness, as is the case here. The solution obtained here is also known as the incomplete 2nd order approximation because vertical pressure is still considered glaciostatic, meaning there are no vertical resistive stresses or bridging effects (Blatter, 1995). Since the horizontal velocities no longer depend on local quantities such as ice thickness and surface slope, as is the case in the shallow-ice approximation, the solution needs to be obtained with iterative methods. The iteration on the nonlinear ice viscosity part is based on a subspace relaxation algorithm, but does not converge very rapidly. Consequently, the FSM is up to 500 times more time consuming than the LSM for a similar grid, and therefore can only be used for a limited area. Moreover, halving the horizontal grid size in prognostic calculations requires four times more memory and increases CPU time by a factor 16 , further limiting the applicability of high-resolution grids to large domains. The vertical velocity field in the nested domain of FSM is obtained through vertical integration of the continuity equation, satisfying kinematic boundary conditions at either the upper or lower ice surfaces.
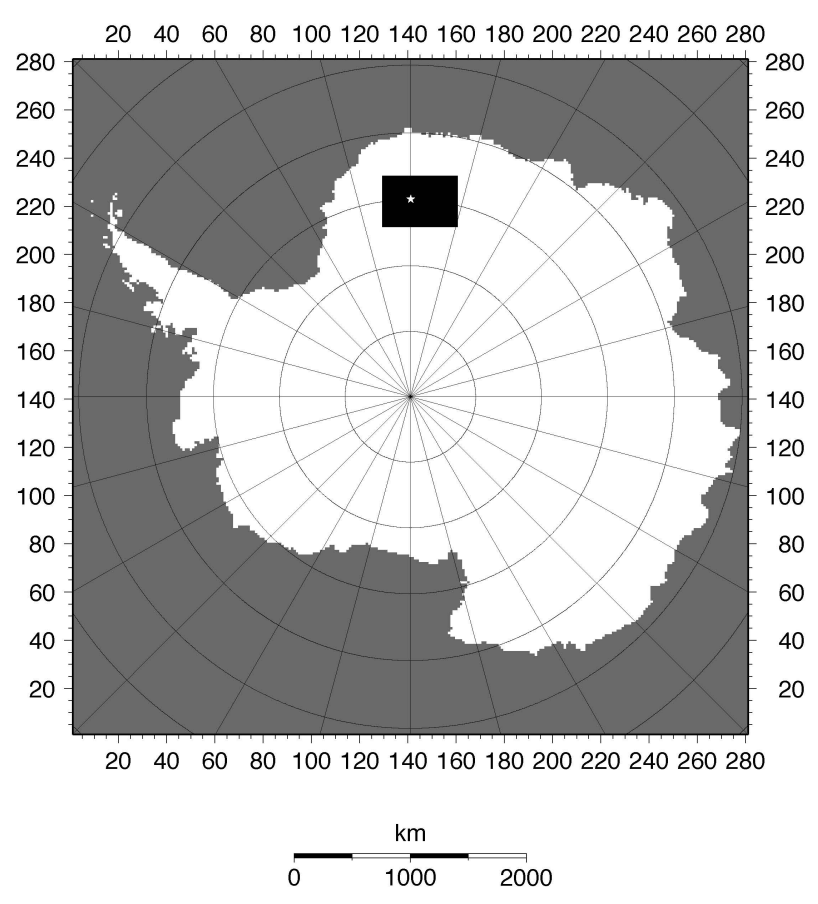

Fig. 1. The Antarctic ice sheet model covers a $281 \times 281$ gridpoint square centered over the South Pole. The black rectangle in eastern Dronning Maud Land shows the model domain of the nested regional model FSM. The white star denotes the location of Kohnen Station $\left(75^{\circ} 00.104^{\prime} \mathrm{S}, 0^{\circ} 04.07^{\prime} \mathrm{E}\right)$.

In this study FSM consists only of the higher-order mechanical equations for the horizontal velocity components as given in Pattyn (2003). The flow law, rheological parameters, and the treatment of basal sliding are identical to LSM. On the $2.5 \mathrm{~km}$ grid employed here FSM computes a significantly more accurate velocity field in response to topographic disturbances (Hindmarsh et al., 2006). Bedrock perturbations inevitably lead to variations in the flow field. These variations are exaggerated in an SIA model, especially at high resolution where horizontal grid sizes approach the ice thickness. This limitation can be overcome by using a coarser grid, but at the expense of a less detailed solution. A higherorder model is insensitive to this effect as long stresses develop where gradients are more pronounced, in effect smearing out the effects of small-scale irregularities (Pattyn et al., 2005). Without FSM we could therefore not have exploited the quality of the detailed observations to the same extent. This is best illustrated by the resulting ice core chronologies, which differed by up to $20 \%$ at $90 \%$ depth between FSM and LSM as obtained from their velocity solutions on their respective grids.

\subsection{Geometric model input and coupling scheme}

Geometric model input was primarily taken from the BEDMAP compilation (Lythe et al., 2001), amended locally in Dronning Maud Land with more recent thickness data 

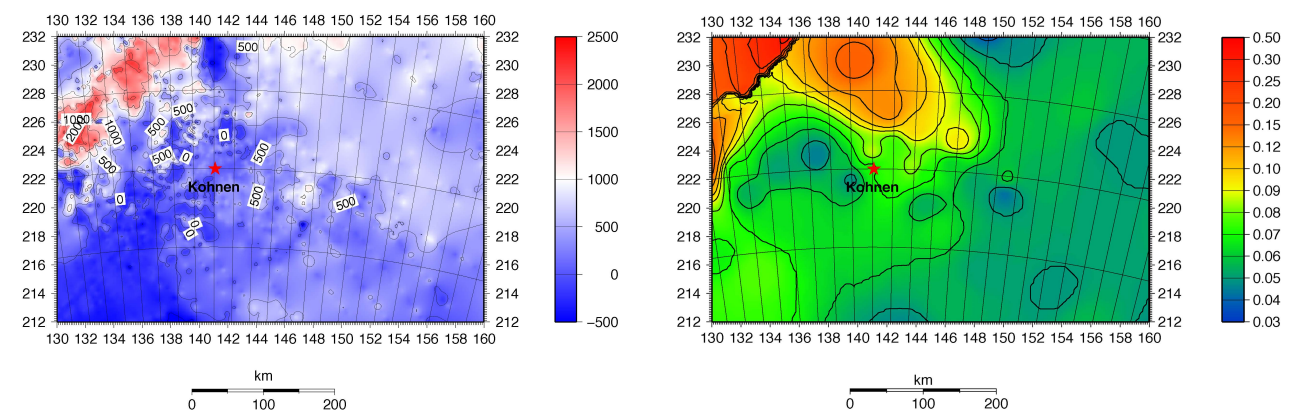

Fig. 2. Fundamental model input on the $2.5 \mathrm{~km}$ grid of the FSM. Left panel: bedrock elevation in m a.s.l.; right panel: present-day accumulation rate in $\mathrm{m} \mathrm{yr}^{-1}$ of ice equivalent. These datasets are a combination of the BEDMAP data and the earlier compilations of Huybrechts et al. (2000) updated with the results of extensive pre-site field surveys conducted by the Alfred Wegener Institute. The integer coordinates of the FSM domain correspond to the $20 \mathrm{~km}$ gridpoints of the LSM.

(Steinhage et al., 2001) and blended with the older datasets for oceanic bathymetry (Huybrechts et al., 2000) to circumvent artefacts in the BEDMAP data at grounding lines and below ice shelves. The bedrock topography in the domain covered by FSM includes the most complete collection of radio-echo-sounding flight lines as obtained by the Alfred Wegener Institute. The flight line separation over the entire area where particle trajectories are located is better than $10 \mathrm{~km}$ with crossover differences in ice thickness less than $10 \mathrm{~m}$ for the majority of cases. Near to Kohnen station the radar profile separation densifies to less than $1 \mathrm{~km}$ due to the radial flight pattern, justifying the $2.5 \mathrm{~km}$ grid resolution employed in FSM. For surface elevation, the $2.5 \mathrm{~km}$ grid is a high-resolution cubic-spline representation of the $20 \mathrm{~km}$ grid, in effect causing surface gradients in FSM to represent average values over a distance of about 10 ice thicknesses as dictated by theory (Paterson, 1994). For ice thickness and bedrock elevation, on the other hand, overlapping gridpoints of FSM and LSM do not have exactly the same values. Figure 2 (left panel) shows the bedrock topography in the nested model domain.

The field of accumulation rate is based on the Giovinetto and Zwally (2000) compilation used in Huybrechts et al. (2000), and updated with accumulation rates obtained from shallow ice cores during the EPICA pre-site surveys (Oerter et al., 1999, 2000; Rotschky et al., 2007). The present-day accumulation rate at Kohnen in this dataset is $7.0 \mathrm{~cm} \mathrm{yr}^{-1}$ of ice equivalent (Fig. 2, right panel).

The coupling between FSM and LSM is performed in a straightforward manner. LSM exchanges information with FSM only in the downward direction; the high-resolution flow solution does not feed back into the Large Scale Model. All information is passed down using cubic-splines as interpolation algorithm (Press et al., 1992). We experimented with two anomaly schemes to transfer changes in geometric variables (surface elevation, ice thickness, and bed elevation). In the first one anomalies, or differences, of LSM variables at time $t$ with respect to the observations are ap- plied. This makes the time-dependent FSM geometry a highresolution representation of the LSM geometry. In order to ensure a smooth transition of ice thickness and horizontal velocities at the lateral boundaries of FSM, a transition zone of $40 \mathrm{~km}$ is defined inside the fine scale grid. The alternative method is to superimpose modeled LSM differences at time $t$ with respect to time zero (present-day) onto the observed FSM geometry. We found the second anomaly scheme to perform better as it prevents systematic deviations in the modeled surface elevation to distort the FSM velocity solution. In the LSM, the modeled location of the ice divide around Kohnen is shifted by about $20 \mathrm{~km}$ to the north with respect to the observations and this would otherwise cause a systematic bias in the calculated flow direction and magnitude. Opting for the second anomaly scheme also ensures that the modeled topography at the present-day coincides with the observations. A potential disadvantage of the second scheme is that mass conservation is not necessarily guaranteed in FSM, but in practice it is. That is because the spatially averaged horizontal velocity field of FSM is close to the one of LSM, and because vertical velocities are corrected to satisfy the kinematic boundary condition at the upper ice surface when starting the integration from the lower ice surface. Fortunately, these vertical velocity corrections, which are scaled linearly with depth, are usually very small. A lateral transition zone is not required in the second anomaly scheme as the FSM and LSM geometries do no longer exactly match. Instead, grid boundary conditions on horizontal velocity are inferred from the shallow-ice approximation but this has a negligible influence on the velocity solution inside the FSM grid. All other variables such as ice temperature (and hence, the rate factor in the flow law), basal melting rate, sliding velocity, time-derivatives of ice thickness and bed elevation are interpolated from LSM on the FSM grid with some additional corrections to ensure internal consistency under a slightly different ice thickness using the dimensionless $\zeta$ coordinate for rescaling. 

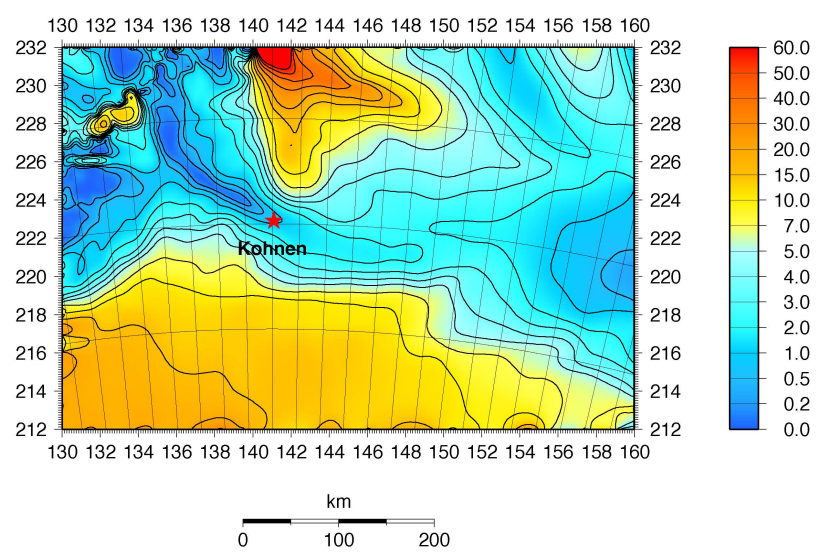

Fig. 3. Modeled present-day horizontal surface velocity $\left(\mathrm{m} \mathrm{yr}^{-1}\right)$ as obtained by the FSM. The modeled value for Kohnen Station of $0.73 \mathrm{~m} \mathrm{yr}^{-1}$ is very close to the observed value of $0.76 \mathrm{~m} \mathrm{yr}^{-1}$. Meridians and parallel circles are both plotted at a $1^{\circ}$ spacing.

The present-day modeled field of horizontal surface velocity in FSM is displayed in Fig. 3. Kohnen station is shown to be located almost exactly on the flow axis with horizontal velocities decreasing downstream when approaching the saddle area. The modeled surface velocity at Kohnen is $0.73 \mathrm{~m} \mathrm{yr}^{-1}$, close to the currently observed surface velocity of $0.76 \mathrm{~m} \mathrm{yr}^{-1}$ (Wesche et al., 2007). The corresponding vertically averaged velocity is $0.65 \mathrm{~m} \mathrm{yr}^{-1}$ from a direction close to westward $\left(279.4^{\circ}\right.$ azimuth in the model compared to $273.4^{\circ}$ observed). The model predicts no basal sliding at Kohnen at present concomitant with a basal temperature $0.3^{\circ} \mathrm{C}$ below the pressure melting point. However, as the EDML drill site is located very close to the melting point and is adjacent to a large wet-based zone further to the south, the pressure melting point was hit intermittently on many occasions during the last few glacial cycles. As present-day melting already occurs for a slightly higher geothermal heat flux of $56 \mathrm{~m} \mathrm{~W} \mathrm{~m}^{-2}$, well within the uncertainty range on this parameter (Fox Maule et al., 2005), the exact history of basal melting at Kohnen is hard to predict. We therefore restrict the analysis of the EDML ice core to the uppermost $89 \%$ which are largely unaffected by the unknown basal boundary condition on temperature and velocity. Field evidence from the drilling itself found subglacial water entering the borehole, indicating pressure melting conditions also today, and consequently, a geothermal heat flux at least $1.4 \mathrm{~m} \mathrm{~W} \mathrm{~m}^{-2}$ higher than assumed by the standard model.

\subsection{Experimental set-up}

The nested model was first integrated over the last $740 \mathrm{kyr}$. This is the period coinciding with the last 8 glacial cycles for which detailed climatic forcing from both Antarctic ice cores and oceanic sediment cores is available. The sea level forcing, which controls grounding-line migration in LSM, was

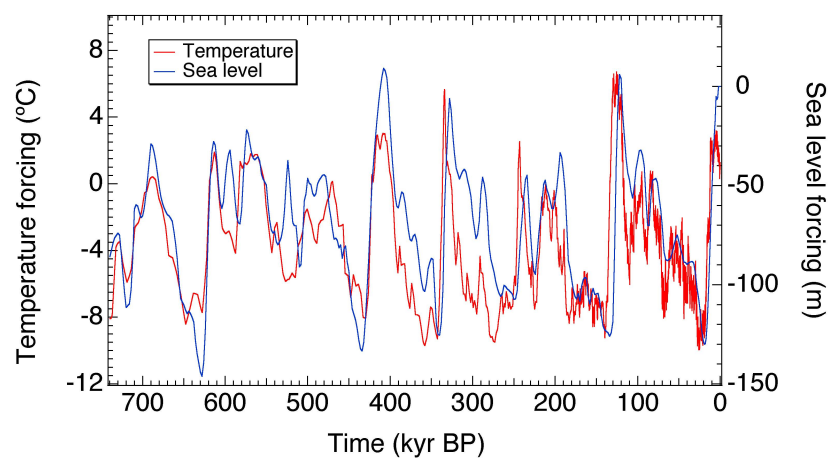

Fig. 4. Climatic forcing records used in the forward experiment over the last 8 glacial cycles. The temperature forcing was assembled from a combined EDC/EDML isotope record subject to surface elevation corrections from a precursor experiment. The sea level forcing record was assembled from the Bassinot and SPECMAP oceanic $\delta^{18} \mathrm{O}$ stacks.

put together by combining a planktonic $\delta^{18} \mathrm{O}$ record from the tropical ocean (Bassinot et al., 1994) with the well-known SPECMAP stack (Imbrie et al., 1984). Both were scaled to obtain a sea-level minimum of $-130 \mathrm{~m}$ at the Last Glacial Maximum and a sea-level maximum of $+6 \mathrm{~m}$ during the Last Interglacial around $122 \mathrm{kyr}$ BP (Chappell and Shackleton, 1986). We took the Bassinot record because its chronology already served to construct age control windows for the dating of the EDC ice core for the period older than $50 \mathrm{ky}$ BP (EPICA community members, 2004). The SPECMAP data provides the sea-level forcing only for the most recent $21 \mathrm{kyr}$ following the Last Glacial Maximum when the Bassinot record is incomplete.

For the temperature forcing, we made use of both the EDC deuterium record (EPICA community members, 2004) for the last $740 \mathrm{kyr}$ and the EDML $\delta^{18} \mathrm{O}$ record for the last $170 \mathrm{kyr}$ (EPICA community members, 2006). These were provided on early 2006 draft versions of the EDML1 and EDC3 time scales, virtually identical to their final forms (Ruth et al., 2007 issue; Parrenin et al., 2007). The correction for the mean isotopic content of the ocean was made following Vimeux et al. (2002) employing the Bassinot et al. (1994) $\Delta \delta^{18} \mathrm{O}_{\text {ocean }}$ scaled for a global mean $\delta^{18} \mathrm{O}$ enrichment of $1 \%$ o at the LGM (Waelbroeck et al., 2002). An iterative procedure was adopted to estimate the climatic part of the ice core signals. First, LSM was run over 740000 years using the $\mathrm{EDC}$ deuterium record with $\partial \mathrm{T}_{s} / \partial \delta \mathrm{D}=0.166^{\circ} \mathrm{C} / \%$. Modeled elevation changes at Dome $\mathrm{C}$ and Kohnen were then used to correct both records for local elevation changes. For the EDML ice core, a first estimate was additionally made for the effect of horizontal advection using LSM fields. Secondly, the corrected EDC temperature was slightly rescaled to the corrected EDML record for the overlapping period to obtain a combined climatic temperature forcing representative for Dronning Maud Land for the last 740 kyr. The fabricated 
forcing records obtained in this way are displayed in Fig. 4. The nested LSM/FSM experiment described in this paper in fact represents one more iteration to obtain the ice core corrections using those pre-determined forcing functions. The local accumulation rate in the large ice sheet and the nested flow model is calculated from the thermodynamical dependence of precipitation rate on the temperature at the elevation of cloud formation over the ice sheet (Jouzel and Merlivat, 1984), using a modification of the Lorius et al. (1985) approach (EPICA community members, 2004):

$$
\begin{aligned}
P_{A}\left[T_{I}(t)\right]= & P_{A}\left[T_{I}(0)\right] \exp \left\{22.47\left[\frac{T_{0}}{T_{I}(0)}-\frac{T_{0}}{T_{I}(t)}\right]\right\} \\
& \left\{\frac{T_{I}(0)}{T_{I}(t)}\right\}^{2}\left\{1+\beta\left[T_{I}(t)-T_{I}(0)\right]\right\}
\end{aligned}
$$

where $P_{A}\left[T_{I}(t)\right]$ is the local accumulation rate at time t, $P_{A}\left[T_{I}(0)\right]$ the present-day accumulation rate at the same place, $T_{0}=273.15 \mathrm{~K}, T_{I}(t)=0.67 T_{S}(t)+88.9$ (in $\mathrm{K}$ ) is the inversion temperature at time $\mathrm{t}$ and $T_{I}(0)$ is the presentday inversion temperature. $\beta$ is a constant fitting parameter. The first part of the relation basically takes into account the temperature-dependent change of saturation vapour pressure, whereas the parameter $\beta$ takes into account glacialinterglacial changes of the accumulation pattern that is not explained by this relationship. $\beta=0.046$ has been empirically determined by comparing upstream accumulation rates derived from firn cores (Oerter et al., 2000; Graf et al., 2002) with the internal layering from an extended surface radar survey along the Kohnen-Dome Fuji radio-echo sounding profile (Steinhage et al., 2001; Rybak et al., 2005). This leads to average glacial accumulation rates around the EDML drill site which are around $45 \%$ of current values. The approach assumes that the current spatial pattern of accumulation rate is conserved through time and that spatially-derived temperature lapse rates are invariant in time.

\section{Backward tracing of particle trajectories}

\subsection{Lagrangian backtracing method}

The forward experiment stores the three-dimensional velocity field, ice thickness, surface elevation, surface temperature, accumulation rate, and other relevant variables for every 100 years in a FSM subdomain that is large enough to embed all possible trajectories. Initially, ice particles are placed at every $0.1 \%$ of ice equivalent thickness (or every $2.75 \mathrm{~m}$ ) at the exact geographical position of the Kohnen drill site. Each particle is then rigorously traced back into time along Lagrangian particle paths using the inverse three-dimensional velocity field interpolated by three-dimensional splines to the exact particle position. This is equivalent to the Particle-inCell method (Harlow, 1964) and the reverse of the method qualitatively described in Reeh (1989) for reconstructing forward particle paths or the method to determine isochrones in numerical ice sheet models (Rybak and Huybrechts, 2003). The time $t$ when the ice particle crosses the ice sheet surface is accepted as the time of origin, or age, of the ice, and the $\mathrm{x}, \mathrm{y}$-coordinates of surface emergence as the place of origin, which information can be further linked to a number of relevant variables. To improve the dating, an algorithm is used to calculate the exact age within a fraction of the time step $\Delta t=100$ years by estimating the time left to reach the surface by the tracer already closest to the surface.

\subsection{Particle trajectories and points of origin}

The left panel of Fig. 5 shows the horizontal projections of all particle trajectories for the upper $89 \%$ of the EDML ice core, plotted on a background representing the present-day observed topography. The deepest particle traveled for 184 $\mathrm{km}$ roughly parallel to a latitudinal circle. Only the deepest particle trajectories are visible on the plot in purple colours, attesting to the stability of the flow pattern and the ice divide position in this region over the time period considered. Apparently all these trajectories followed almost the same path with a maximum bandwidth of less than $2 \mathrm{~km}$. The right panel of Fig. 5 shows the same particle trajectories, but now coloured as a function of time. The gradual change of colours again attests to the relatively constant flow magnitude along the ridge which varied around $1 \mathrm{~m} \mathrm{yr}^{-1}$ for most of the trajectories during the last $170 \mathrm{kyr}$.

The points of origin where Kohnen particles were originally deposited is displayed in Fig. 6 as a function of EDML depth and time of deposition. It is found that the deepest particle ending up at $89 \%$ relative depth was deposited $169.9 \mathrm{kyr}$ ago at the ice sheet's surface. As the time of deposition is equivalent to the age of a particle, these results immediately yield the chronology of Kohnen ice.

\subsection{Ice core chronology}

The modeled age of the EDML ice is shown in Fig. 7. This time scale is obtained separately from the official synchronized EDML1 chronology (Ruth et al., 2007) and is based solely on our best assumptions for modeling ice dynamics in the region and the adopted fixed relation between palaeotemperatures and palaeo-accumulation rates. There is no a posteriori fine tuning nor the use of age control windows or fixed points involved. Our modelled time scale also does not depend very strongly on the exact chronology of the temperature and sea-level forcing itself. In fact, any East Antarctic temperature record would have provided very similar results insofar the same glacial-interglacial contrast in accumulation rates would have resulted, as provided by appropriate tuning of Eq. (1) and/or appropriate scaling of the glacial-interglacial temperature difference. The modelled ice-age versus depth profile has the expected shape close to exponential resulting from regular ice thinning under conditions of vertical shear, with slope breaks which correspond 

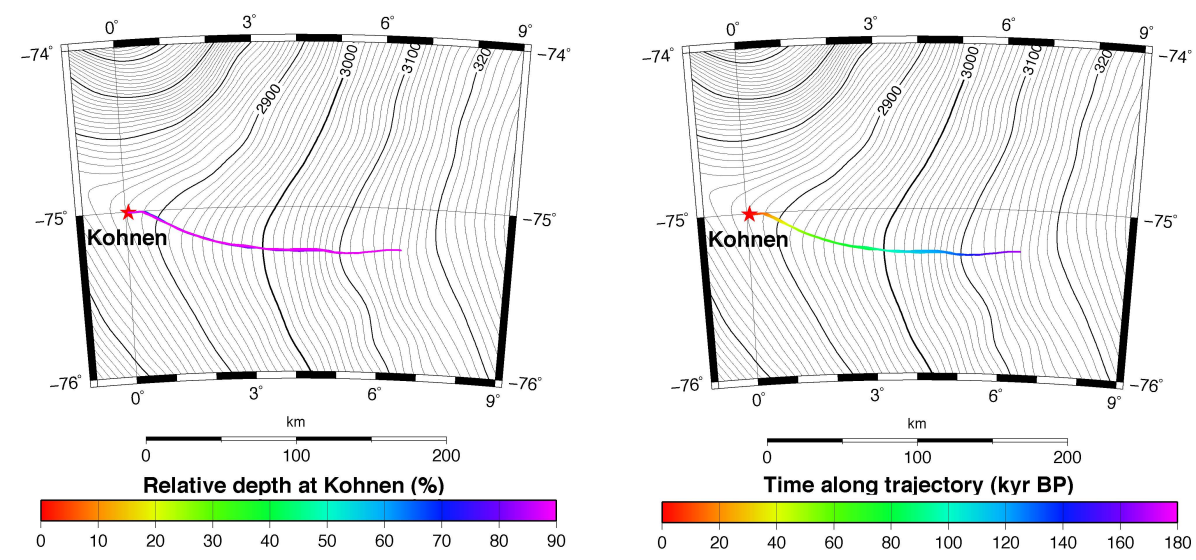

Fig. 5. Horizontal projection of ice particle trajectories placed at every $1 \%$ i.e. depth in the Kohnen drill site. The colour coding in the left panel is for their final depth at Kohnen. In the right panel the colours indicate the time along any individual trajectory. Since most trajectories follow similar paths, the younger ones are overlain by the deepest particle trajectories which travelled furthest. The background contour lines are for the present-day surface elevation. Results are only shown for the uppermost $89 \%$ of the ice core.
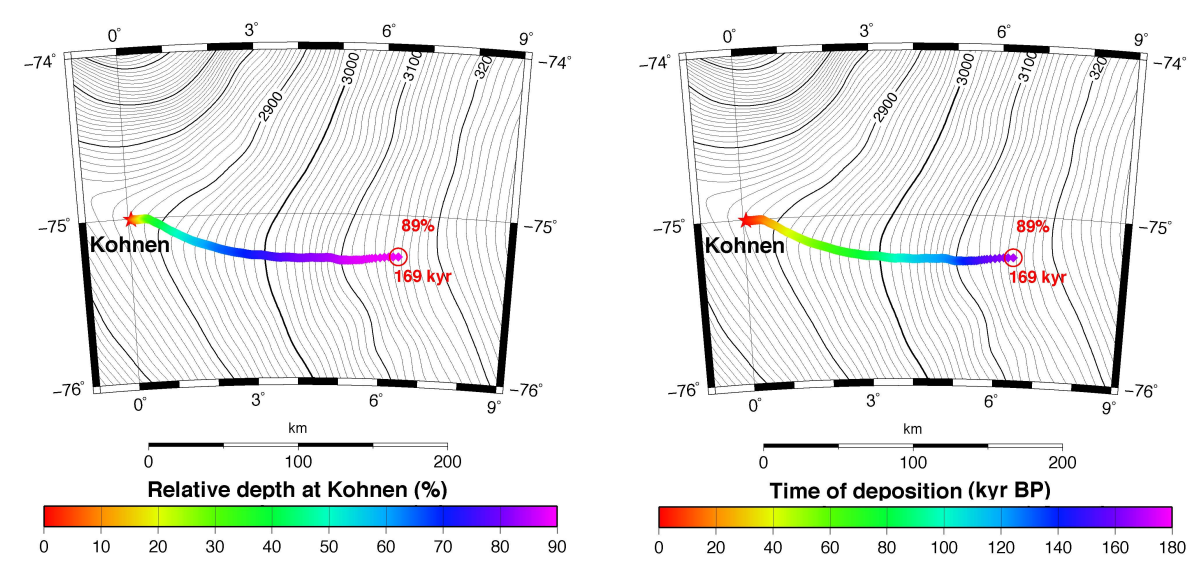

Fig. 6. Places of origin for particles placed at every $1 \%$ i.e. depth in the Kohnen drill site. These are shown as a function of relative depth at Kohnen (left panel) and time of deposition (right panel). The background contour lines are for the present-day surface elevation. Results are only shown for the uppermost $89 \%$ or $169 \mathrm{kyr}$ of the ice core.

to glacial-interglacial shifts in accumulation rate, and hence, initial ice layer thickness at the surface.

Comparing our glaciologically derived chronology with EDML1 shows an excellent agreement for most of the profile. This proves the validity and internal consistency of the modeled velocity fields and gives confidence in our particle trajectory method. The agreement is very good for the Holocene and long time intervals during the last glacial period with a maximum age difference of less than 300 years. Somewhat larger differences are seen for several segments below $1000 \mathrm{~m}$ depth of up to $1750 \mathrm{yr}$ at $1760 \mathrm{~m}$ and at $2110 \mathrm{~m}$ depth. The most conspicuous deviation from EDML1 however takes place for the bottom part of the comparison below $2380 \mathrm{~m}$ (ice older than $130 \mathrm{kyr}$ ) where EDML1 gives considerably older ages than our modelling. The reasons for these mismatches are however unclear, in particular as they do not seem to be of a systematic nature. They may indicate that the assumptions made in the flow modeling are invalid during certain time periods. One possibility could be that the relation between $\delta^{18} \mathrm{O}$, surface temperature, and accumulation rate does not apply at all times in the past. However, given the relatively small deviations between both chronologies for the last glacial period, it is difficult to see why the relation between surface temperature and saturated vapour pressure above the inversion layer, well established for the last glacial period, should not apply for the penultimate glacial period, where suddenly a larger difference between both chronologies occurs. Alternatively, the ice dating may also crucially depend on vertical variations in ice hardness or ice fabric that are not taken into account in the isotropic flow law used for the modeling. Such hardness contrasts and possible anisotropic deformation regimes cause anomalies in the 


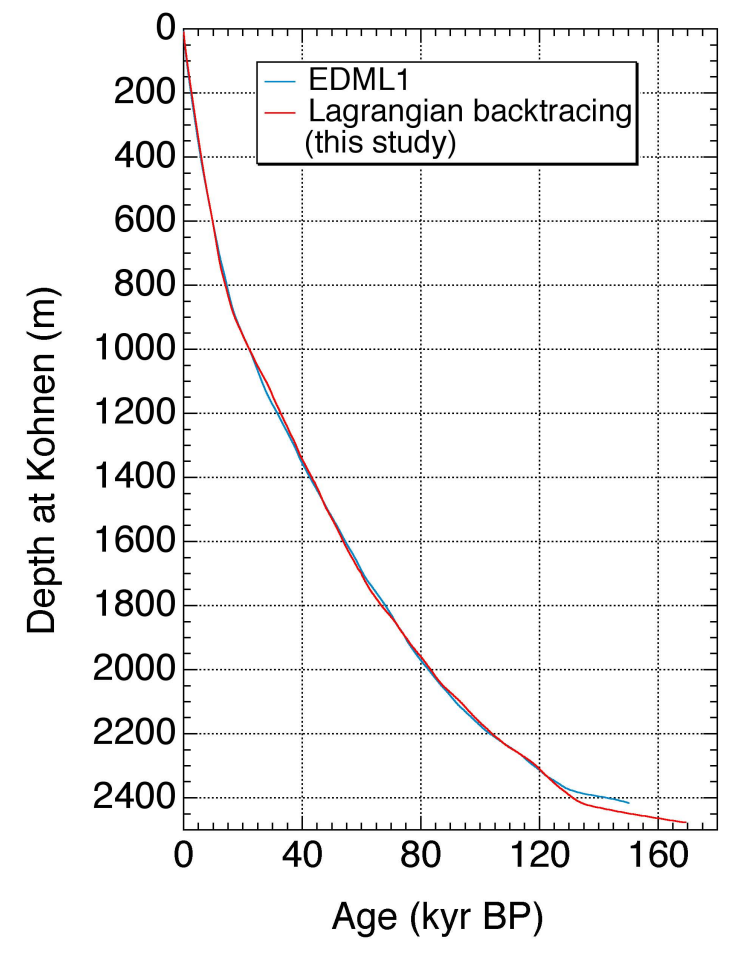

Fig. 7. Model-derived depth-age distribution at Kohnen plotted as function of real depth. For comparison, the EDML1 time scale obtained from stratigraphic matching with the EDC ice core is shown in blue (Ruth et al., this issue). Both curves agree very well, but less so for the penultimate glacial period between 125 and $150 \mathrm{kyr}$ BP.

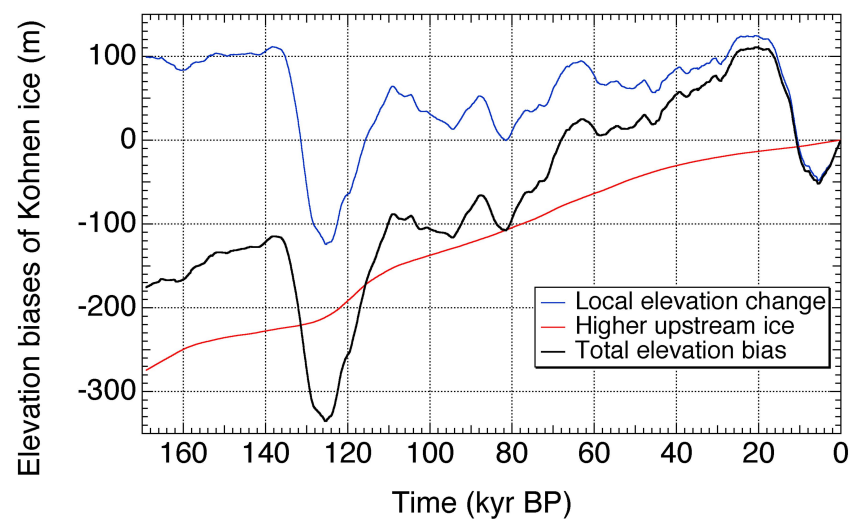

Fig. 8. Differences in surface elevation $(\mathrm{m})$ of Kohnen ice with respect to its present-day elevation shown as a function of time. The total elevation bias (black line) has a component due to horizontal advection (red line, given as the elevation difference between Kohnen and the place of origin of the ice particle for present-day topography) and due to the local elevation change at the point of particle origin at the time of deposition (blue line, given as the elevation difference at the place of origin between today and the time of origin). thinning function, but a definite proof of their occurrence at this depth has yet to be given. Unless the mismatches are caused by model errors or other physical mechanisms we are unaware of, it is also possible that the stratigraphic matching and/or the EDC3 chronology are imprecise. That may especially be the case for the bottom part below $2350 \mathrm{~m}$ where confidence in the synchronization method is lower (Ruth et al., 2007); however, investigations have shown that possible stratigraphic mismatches could only account for part of the observed deviations. Therefore it seems likely that the mismatches between the purely glaciologically derived time scale and EDML1 is some combination of all the factors mentioned above. We can probably exclude the role of possible basal melting upstream of the Kohnen drill site, because any basal melting would have made the modelled ice even younger as compared to EDML1, and our standard model predicts continuously frozen conditions. Finally, it is interesting to note that tentative extensions of both chronologies not shown here seem to match up again around $180 \mathrm{ky}$.

\section{Non-climatic biases}

Since ice particles have recorded physical conditions at the time and place of origin, it is clear from the preceding discussion that this information is contaminated by elevation changes. Any climatic interpretation of ice core variables therefore needs to be corrected for these elevation changes. The older the ice at Kohnen, the further upstream it was deposited. Since particle trajectories approximately followed a circle of latitude, we can neglect latitudinal climatic gradients. We define non-climatic biases as a function of the elevation difference between the original altitude at particle deposition and the present-day altitude of Kohnen. A distinction is made between a bias due to advection $\Delta S_{\text {adv }}$ and one due to the local elevation change $\Delta S_{\text {loc }}$ :

$$
\begin{aligned}
& \Delta S_{\mathrm{adv}}(t)=S_{\mathrm{EDML}}(0)-S_{x y}(0) \\
& \Delta S_{\mathrm{loc}}(t)=S_{x y}(0)-S_{x y}(t) \\
& \Delta S_{\mathrm{tot}}(t)=\Delta S_{\mathrm{adv}}(t)+\Delta S_{\mathrm{loc}}(t)
\end{aligned}
$$

where $\Delta S_{\text {tot }}$ is the total elevation bias and the subscripts $x y$ and EDML refer to the place of deposition and the current location of the EDML ice core, respectively.

These elevation biases are shown in Fig. 8 as a function of time. The advection bias from the higher upstream ice shows up as a systematic decline modulated by both surface slope and horizontal speed of advection. For the time span considered here, $\Delta S_{\text {adv }}$ equals $-275 \mathrm{~m}$ by $170 \mathrm{kyr}$ BP. Superimposed on this systematic trend are the effects of local elevation changes. These are primarily driven by accumulation changes, on which the effects of deeper ice temperature and to a lesser extent, grounding line changes at the coast, are superimposed. The local elevation bias $\Delta S_{\text {loc }}$ has a typical glacial-interglacial amplitude of $200 \mathrm{~m}$ (peak to peak) 
in this part of Dronning Maud Land. It is positive during glacial periods commensurate with the lower accumulation rates, and hence, lower elevations. At present, the surface at Kohnen is lowering at a rate of $8.7 \mathrm{~m} \mathrm{kyr}^{-1}$, corresponding to a combination of slightly lower accumulation rates since the mid-Holocene, slight warming in the basal deformational layers, and the effects of a thinning wave originating from grounding-line retreat after the Last Glacial Maximum. These responses are very similar to those discussed in Huybrechts (2002). Because of the damming effect of the Maudheimvidda mountain range on the flow, grounding-line changes in both East and West Antarctica exert only a relatively minor influence on this part of Dronning Maud Land. As the effect of accumulation is dominant, elevation changes along the flowlines mainly scale with the local accumulation rate compared to Kohnen, and are moreover approximately synchronous with Kohnen. The local elevation bias is dominant for the upper half of the ice core but below that the upstream advection bias is most important. The maximum total elevation bias $\Delta \mathrm{S}_{\text {tot }}$ of $-335 \mathrm{~m}$ relative to present-day occurs during the Last Interglacial at $125.2 \mathrm{kyr}$ BP when accumulation rates were highest and the ice was deposited about $150 \mathrm{~km}$ inland at a current elevation $220 \mathrm{~m}$ higher than today. In Fig. 9 the same non-climatic biases are plotted as a function of depth at Kohnen using the modeled age to depth time scale.

To transform these elevation biases into temperature and $\delta^{18} \mathrm{O}$ corrections present-day spatial correlations between 10-m firn temperature, surface elevation, and mean surface $\delta^{18} \mathrm{O}$ need to be established. This was done using a subset of the pre-site survey data located upstream from Kohnen (Oerter et al., 1999, 2000; Graf et al., 2002). The linear relations resulting from this regression are shown in Fig. 10. Consequently, non-climatic biases on surface temperature and $\delta^{18} \mathrm{O}$ are found as:

$$
b_{\mathrm{tot}}^{T}(t)=b_{\mathrm{adv}}^{T}(t)+b_{\mathrm{loc}}^{T}(t)=\Delta S_{\mathrm{adv}}(t) \frac{\partial T_{S}}{\partial S}+\Delta S_{\mathrm{loc}}(t) \frac{\partial T_{S}}{\partial S}(5)
$$

$$
\begin{aligned}
b_{\mathrm{tot}}^{\delta^{18} O}(t)= & b_{\mathrm{adv}}^{\delta^{18} O}(t)+b_{\mathrm{loc}}^{\delta^{18} O}(t)=\Delta S_{\mathrm{adv}}(t) \frac{\partial \delta^{18} O}{\partial S} \\
& +\Delta S_{l o c}(t) \frac{\partial \delta^{18} O}{\partial S}
\end{aligned}
$$

where $\mathrm{b}$ is the non-climatic bias and $\partial T_{S} / \partial S=-0.01171^{\circ} \mathrm{C}$ $\mathrm{m}^{-1}$ and $\partial \delta^{18} O / \partial S=-0.00957 \% \circ \mathrm{m}^{-1}$. The usual assumption is made that present-day spatial gradients are a good approximation for temporal gradients (Jouzel et al., 1997). This need not necessarily be the case. For example, Krinner and Genthon (1999) established from numerical experiments with AGCMs that the temporal Antarctic lapse rate at 3000 $\mathrm{m}$ elevation may be somewhat lower at $\partial T_{S} / \partial S=-0.009^{\circ} \mathrm{C}$ $\mathrm{m}^{-1}$. If so, our non-climatic temperature bias may be overestimated by about $25 \%$.

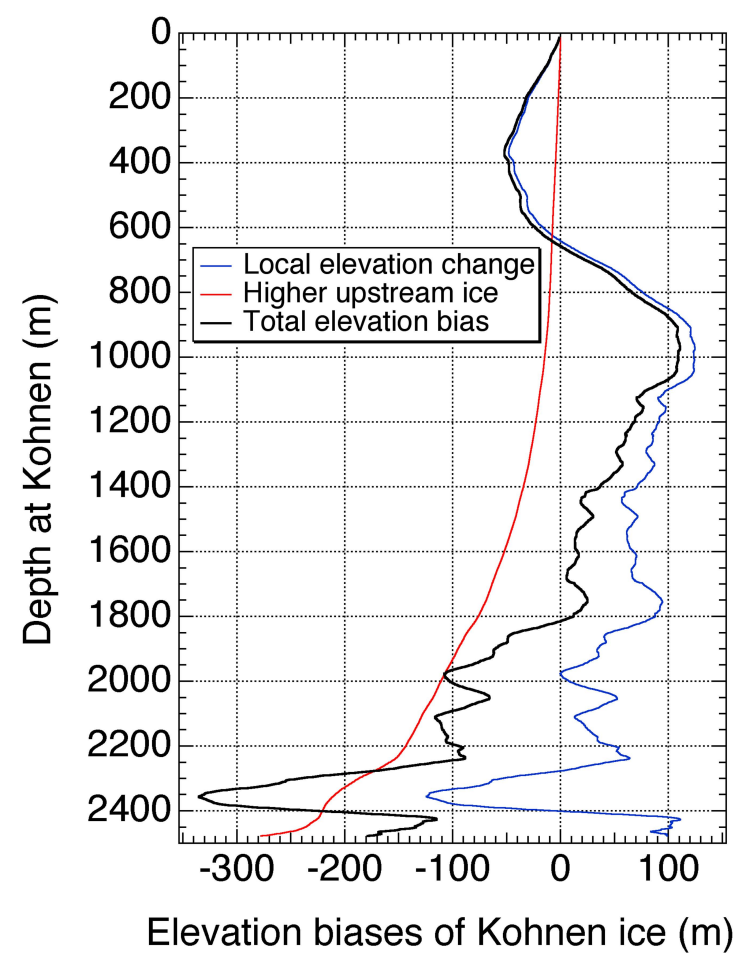

Fig. 9. Same biases as in Fig. 8 but plotted as a function of depth at Kohnen using the modeled depth-age distribution.

Final non-climatic corrections for surface temperature and $\delta^{18} \mathrm{O}$ are shown in Fig. 11 as a function of time. These are the values which need to be added to the measured $\delta^{18} \mathrm{O}$ ratios obtained directly from the EDML ice core. Apparently, the LGM was about $1^{\circ} \mathrm{C}$ cooler and MIS 5.5 up to $4^{\circ} \mathrm{C}$ warmer than evident from the uncorrected ice core data themselves because of the elevation biases. These corrections amount to about half of the range of the original data for the older ice analysed in this paper, which is certainly not negligible. The elevation biases are generally also of larger magnitude than the oceanic correction required to account for changes in the mean $\delta^{18} \mathrm{O}$ composition of the oceans (EPICA community members, 2006). A complete list of the non-climatic biases is also given in the supplementary Tables S1 and S2 (http://www.clim-past.net/3/577/2007/ cp-3-577-2007-supplement.zip).

\section{Thinning function}

Another output of the backtracing method is the layer thinning function, defined as the ratio between annual layer thickness in the EDML ice core and the (ice) accumulation rate at the place and time of deposition at the ice sheet's surface. This is a useful quantity for instance to derive palaeoaccumulation rates from an independently dated ice core. The following relations hold between annual layer thickness 

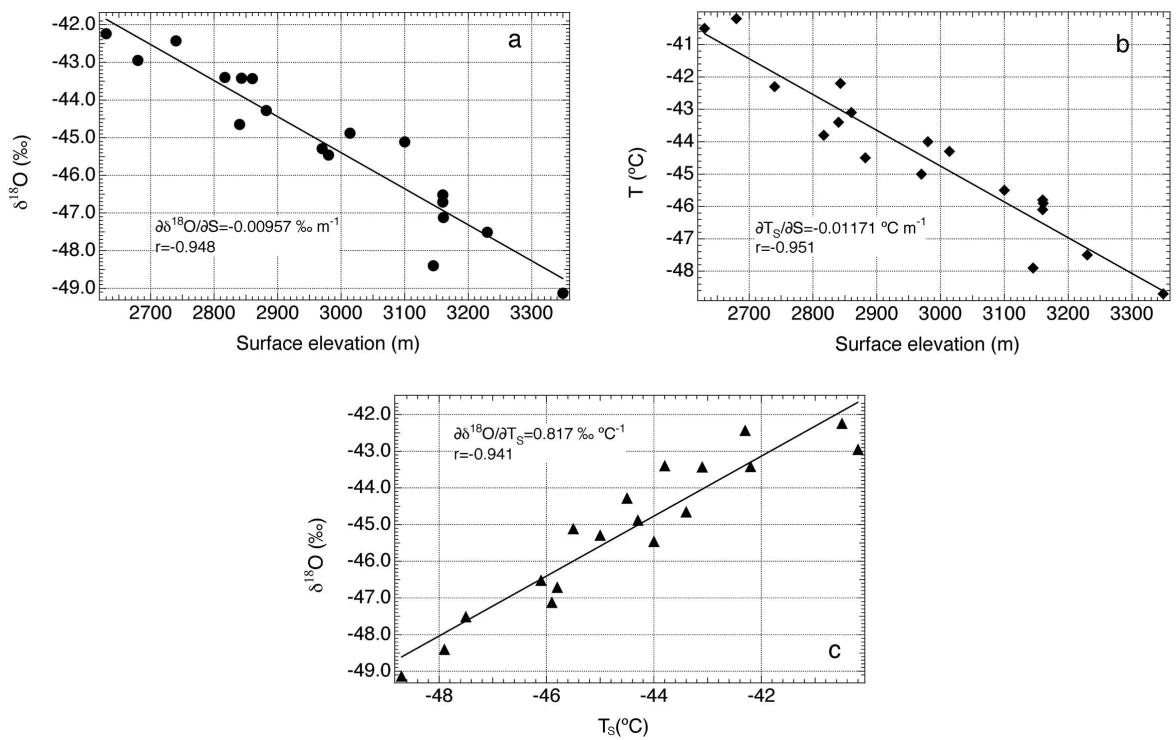

Fig. 10. Linear regression relations between present-day surface elevation $(\mathrm{S}$, in $\mathrm{m})$, surface temperature $\left(\mathrm{T}_{s}\right.$, in $\left.{ }^{\circ} \mathrm{C}\right)$ and oxygen-isotope value of surface snow $\left(\delta^{18} \mathrm{O}\right.$, in \%o) for a selection of field sites upstream of the Kohnen drill site (Oerter et al., 1999, 2000). The calculated presentday spatial gradients are used to transform the modeled elevation changes into non-climatic biases and to correct the initial temperature forcing record. The high values of the correlation coefficients $r$ attest as to the validity of the linear relationships.

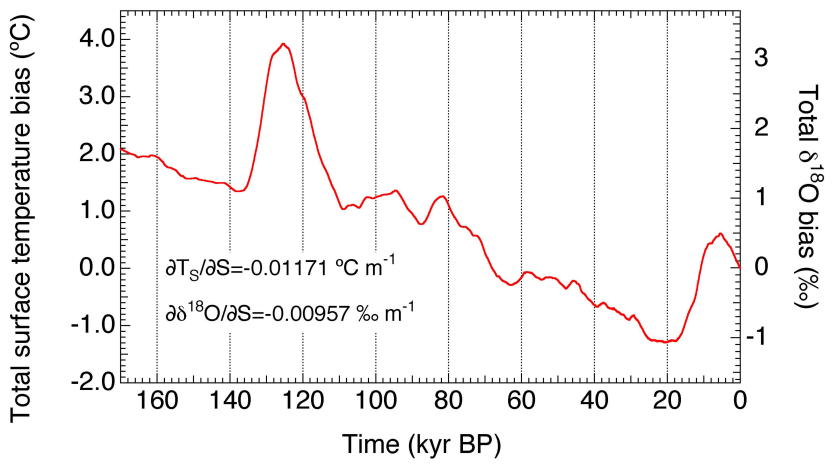

Fig. 11. Total non-climatic biases for the last $169 \mathrm{kyr}$ in the EDML ice core displayed both as a function of surface air temperature $\left({ }^{\circ} \mathrm{C}\right.$, left axis) and of $\delta^{18} \mathrm{O}$ value (\%o, right axis) using the linear relations shown in Figure 10.

$\lambda(z)$, ice age $A(z)$, accumulation rate $P_{A}(z)$, and thinning function $R(z)$, e.g. Reeh (1989), Parrenin et al. (2004):

$$
\begin{aligned}
& A(z)=\int_{0}^{z} \frac{d z^{\prime}}{P_{A}\left(z^{\prime}\right) R\left(z^{\prime}\right)} \\
& R(z)=\frac{\lambda(z)}{\lambda_{0}}
\end{aligned}
$$

where $\lambda_{0}=P_{A}(t)$ is the initial annual layer thickness at the surface.

In our calculations the strain thinning function was rigorously derived from tracing back the layer thickness at a cer- tain depth in the ice core to the original accumulation rate at the surface over exactly the same time interval. This required taking much smaller time steps in the Lagrangian backtracing algorithm than the standard 100 years for the last $50 \mathrm{kyr}$. Additionally, a correction was made for firn compaction in the upper $180 \mathrm{~m}$ by fitting a relation for firn density $\rho(z)$ to the observed density profile of the B32 core (Oerter and Wilhelms, 2001) obtained by dielectric profiling (Wilhelms, 2005):

$\rho(z)=\rho_{0}-\left(\rho_{0}-\rho_{\text {sur }}+\rho_{c}\right) \exp (a z)+\rho_{c}$

where $\rho_{0}=910 \mathrm{~kg} \mathrm{~m}^{-3}$ the density of ice, $\rho_{\text {sur }}=350 \mathrm{~kg} \mathrm{~m}^{-3}$ snow density at the surface, $a=-0.0212 \mathrm{~m}^{-1}$, and $\rho_{c}=12.329 \mathrm{~kg} \mathrm{~m}^{-3}$ a fitting constant to obtain a smooth density transition at $180 \mathrm{~m}$ real depth. The depth $z$ is taken positive downwards.

The result is displayed in Fig. 12 and tabulated in the supplemental Table S2 (http://www.clim-past.net/3/577/2007/ cp-3-577-2007-supplement.zip). As expected, the thinning function is approximately linear when referred to ice equivalent depth, as shown in the inset, and larger than 1 for the upper $180 \mathrm{~m}$ when firn density is taken into account. A conspicuous wiggle is however observed between 1600 and $1720 \mathrm{~m}$ depth, corresponding to the time period between 55 and $63 \mathrm{kyr}$ BP. Such wiggles in the thinning function have been inferred previously for the Vostok ice core (Parrenin et al., 2004) and have been ascribed to undulations in the bedrock topography and spatio-temporal variations in horizontal velocity, accumulation rate, flow divergence and basal melting (Parrenin et al. 2006). Here we suspect that the 


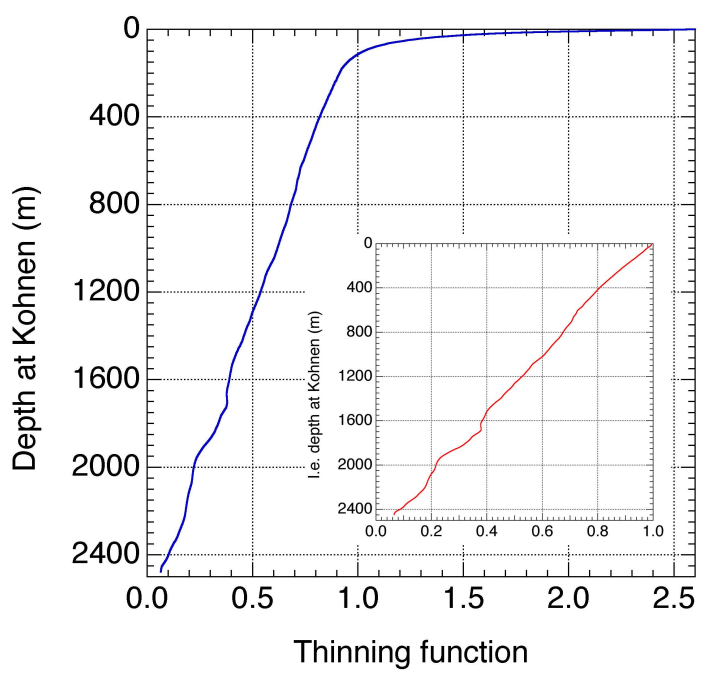

Fig. 12. Thinning function at Kohnen plotted as a function of depth. The blue line is plotted versus real depth and was corrected for a variable firn density in the upper $180 \mathrm{~m}$. The inset shows the original thinning function obtained in the experiment as a function of ice equivalent depth.

"anomalously high" values for the thinning function between 1600 and $1720 \mathrm{~m}$ depth were caused by bedrock highs at around $60 \mathrm{~km}$ upstream from Kohnen station as these are the only irregular features corresponding to the approximate time and place of deposition at this depth in the core. Note, however, that the wiggle in the thinning function between 1600 and $1720 \mathrm{~m}$ depth is not correlated with any of the mismatches between our modeled time scale and EDML1 as the age mismatches occur at depths where the thinning function shows no obvious features.

\section{Conclusions}

In this paper a novel method was presented to date the EDML ice core and separate its climatic information from topographic effects. The main strength of the method is that it is self-contained and largely independent from the specific palaeo-climatic information retrieved from the ice core. The Lagrangian backtracing method in a nested model could as well have been successfully applied to a virtual location elsewhere on the Antarctic plateau without the need of a priori information about past climatic conditions in that particular site provided geometric boundary conditions such as ice thickness are sufficiently well known.

The general good agreement between our glaciologically derived time scale and the official EDML1 time scale provides a good validation of the models and the method, and therefore lends credibility to apply the method also at other (virtual) sites. It was demonstrated that because of its flank position, deeper ice at Kohnen progressively recorded cli- mate from higher upstream positions increasingly less representative for the current drill site. Non-climatic temperature biases from variations of surface elevation were found to amount to up to half of the climate changes retrieved from the ice core itself for the Last Interglacial period. Since the thinning function depends primarily on ice dynamics, any discrepancy between the model-derived age-depth distribution and the one derived from another dating technique should preferentially be interpreted in terms of anomalous accumulation rates, provided substantial changes in ice rheology along the vertical can be excluded.

Sensitivity tests not discussed further in this paper brought to light that the elevation changes and upstream flow corrections are robust to our most important model parameters, at least for the upper $\sim 90 \%$ of the EDML ice core. Below that, the model chronology and derived characteristics are affected much more by the uncertainties on the basal boundary condition, especially on the unknown amount of basal melting. Extending the analysis to these basal layers will require additional efforts to account for the potential range on the geothermal heat flux one could reasonably expect in this part of Dronning Maud Land. The age of the basal ice and the horizontal distance it travelled is moreover expected to increasingly depend on possible ice flow anomalies resulting from fabric evolution or other deformational defects. A clear and unique solution to the age of the bottom ice may therefore be difficult to obtain from straightforward modeling alone, requiring additional constraints from detailed analyses of the ice core itself.

Acknowledgements. The authors wish to thank K. Ketelsen (DKRZ) for essential help to adapt the model code for parallel computing and S. Frickenhaus (AWI) for fruitful discussions concerning performance of the numerical experiments in the early stage of the research. Discussions with C. Ritz and F. Parrenin (LGGE) as well as with F. Wilhelms (AWI) were also greatly appreciated, as were thoughtful reviewer comments from R. Hindmarsh, an anonymous referee, and the editor. Part of the work was supported by the Belgian Research Programmes on the Antarctic and on Science for a Sustainable Development (Belgian Federal Science Policy Office) under contracts EV/11/08A (AMICS) and $\mathrm{SD} / \mathrm{CA} / 02 \mathrm{~A}$ (ASPI). This work is a contribution to the European Project for Ice Coring in Antarctica (EPICA), a joint European Science Foundation/European Commission scientific programme, funded by the EU (EPICA-MIS) and by national contributions from Belgium, Denmark, France, Germany, Italy, the Netherlands, Norway, Sweden, Switzerland and the United Kingdom. The main logistic support was provided by IPEV and PNRA (at Dome C) and AWI (at Dronning Maud Land). This is EPICA publication no. 178.

Edited by: F. Parrenin 


\section{References}

Bassinot, F. C., Labeyerie, L. D., Vincent, E., Quidelleur, X., Shakelton, N. J., and Lancelot, Y.: The astronomical theory of climate and the age of the Brunhes-Matuyama magnetic reversal, Earth Planet. Sci. Lett., 126, 91-108, 1994.

Blatter, H.: Velocity and stress fields in grounded glaciers: a simple algorithm for including deviatoric stress gradients, J. Glaciol., 41(138), 333-344, 1995.

Chappell, J. and Shackleton, N. J.: Oxygen isotopes and sea level, Nature, 324, 137-140, 1986.

EPICA community members: Eight glacial cycles from an Antarctic ice core, Nature, 429, 623-628, 2004.

EPICA community members: One-to-one interhemispheric coupling of polar climate variability during the last glacial, Nature, 444, 19-5-198, 2006.

Fortuin, J. P. F. and Oerlemans, J.: Parameterisation of the annual surface temperature and mass balance of Antarctica, Ann. Glaciol., 14, 78-84, 1990.

Fox Maule, C., Purucker, M. E., Olsen, N., and Mosegaard, K.: Heat Flux Anomalies in Antarctica Revealed by Satellite Magnetic Data, Science 309, 464-467, 2005.

Giovinetto, M. B. and Zwally, H. J.: Spatial distribution of net surface accumulation on the Antarctic ice sheet, Ann. Glaciol., 31, 171-178, 2000.

Graf, W., Oerter, H., Reinwarth, O., Stichler, W., Wilhelms, F., Miller, H., and Mulvaney, R.: Stable-isotope records from Dronning Maud Land, Antarctica, Ann. Glaciol., 35, 195-201, 2002.

Harlow, F. H.: The particle-in-cell computing method for fluid dynamics, Methods of Computational Physics, 3, 319-343, 1964.

Hindmarsh, R. C. A., Leysinger Vieli, G. J.-M. C., Raymond, M. J., and Gudmundsson, G. H.: Draping or Overriding: The Effect of Horizontal Stress Gradients on Internal Layer Architecture in Ice-Sheets, J. Geophys. Res., 111, F02018, doi:10.1029/2005JF000309, 2006.

Hutter, K.: Theoretical Glaciology: material science of ice and the mechanics of glaciers and ice sheets, D. Reidel Publishing Co, Dordrecht etc, 1983, $510 \mathrm{p}$.

Huybrechts, P.: Sea-level changes at the LGM from ice-dynamic reconstructions of the Greenland and Antarctic ice sheets during the glacial cycles, Quat. Sci. Rev., 21, 203-231, 2002.

Huybrechts, P. and de Wolde, J.: The Dynamic Response of the Greenland and Antarctic Ice Sheets to Multiple-Century Climatic Warming, J. Climate, 12, 2169-2188, 1999.

Huybrechts, P., Steinhage, D., Wilhelms, F., and Bamber, J. L.: Balance velocities and measured properties of the Antarctic ice sheet from a new compilation of gridded data sets for modeling, Ann. Glaciol., 30, 52-60, 2000.

Imbrie, J.Z., Hays, J.D., Martinson, D.G., MacIntyre, A., Mix, A.C., Morley, J.J., Pisias, N.G., Prell, W.L., Shackleton, N.J.: The orbital theory of Pleistocene climate: support from a revised chronology of the marine $\delta^{18} \mathrm{O}$ record, in: Milankovitch and Climate, edited by: Berger, A., Imbrie, J. Z., Hays, J. D., Kukla, G., and Saltzman, B., 269-305, D. Reidel, Dordrecht., 1984.

Jouzel, J. and Merlivat, L.: Deuterium and oxygen 18 in precipitation: modelling of the isotopic effects during snow formation, $\mathrm{J}$. Geophys. Res., 89(D7), 11 749-11 757, 1984.

Jouzel, J., Alley, R. B., Cuffey, K. M., Dansgaard, W., Grootes, P., Hoffmann, G., Johnsen, S. J., Koster, R. D., Peel, D., Shuman, C. A., Stievenard, M., Stuiver, M., and White, J.: Validity of the temperature reconstructions from water isotopes in ice cores, J. Geophys. Res, 102(C12), 26471-26487, 1997.

Krinner, G. and Genthon, C.: Altitude dependence of the ice-sheet surface climate, Geophys. Res. Let., 26, 2227-2230, 1999.

Lorius, C., Jouzel, J., Ritz, C., Merlivat, L., Barkov, N. I., Korotkevich, Y. S., and Kotlyakov, V. M.: A 150000 -year climatic record from Antarctic ice, Nature, 316, 591-596, 1985.

Lythe, M., Vaughan, D. G., and the BEDMAP Consortium: BEDMAP: a new ice thickness and subglacial topographic model of Antarctica, J. Geophys. Res., 106(B6), 11 335-11 352, 2001.

Oerter, H., Graf, W., Wilhelms, F., Minikin, A., and Miller, H.: Accumulation studies on Amundsenisen, Dronning Maud Land, Antarctica, by means of tritium, dielectric profiling and stableisotope measurements: first results from the 1995-96 and 199697 field seasons, Ann. Glaciol., 29, 1-9, 1999.

Oerter, H., Wilhelms, F., Jung-Rothenhäusler, F., Göktas, F., Miller, H., Graf, W., and Sommer, S.: Accumulation rates in Dronning Maud Land, Antarctica, as revealed by dielectric-profiling measurements of shallow firn cores, Ann. Glaciol., 30, 27-34, 2000.

Oerter, H. and Wilhelms, F.: Physical properties of firn core DML05C98_32 (B32), PANGAEA, doi:10.1594/PANGAEA.58815, 2001.

Parrenin, F., Rémy, F., Ritz, C., Siegert, M. J., and Jouzel, J.: New modeling of the Vostok ice flow line and implication for the glaciological chronology of the Vostok ice core, J. Geophys. Res., 109(D20), D20102, doi:10.1029/2004JD004561, 2004.

Parrenin, F., Hindmarsh, R. C. A., and Rémy, F: Analytical solutions for the effect of topography, accumulation rate variations and flow divergence on isochrone layer geometry, J. Glaciol., 52(177), 191-202, 2006.

Parrenin, F., Barnola, J.-M., Beer, J., Blunier, T., Castellano, E., Chappellaz, J., Dreyfus, G., Fischer, H., Fujita, S., Jouzel, J., Kawamura, K., Lemieux-Dudon, B., Loulergue, L., MassonDelmotte, V., Narcisi, B., Petit, J.-R., Raisbeck, G., Raynaud, D., Ruth, U., Schwander, J., Severi, M., Spahni, R., Steffensen, J. P., Svensson, A., Udisti, R., Waelbroeck, C., and Wolff, E.: The EDC3 chronology for the EPICA Dome C ice core, Climate of the Past, 3, 485-497, 2007.

Paterson, W. S. B.: The physics of glaciers, $3^{r d}$ edition, Elsevier, Oxford, New York, Tokyo, 1994, 480 p.

Pattyn, F.: A new three-dimensional higher-order thermomechanical ice sheet model: Basic sensitivity, ice stream development, and ice flow across subglacial lakes, J. Geophys. Res., 108(B8), 2382, doi:10.1029/2002JB002329, 2003.

Pattyn, F., Nolan, M., Rabus, B., and Takahashi, S.: Localized basal motion of a polythermal Arctic glacier: McCall Glacier, Alaska, USA, Ann. Glaciol., 40, 47-51, 2005.

Petit, J. R., Jouzel, J., Raynaud, D., Barkov, N. I., Barnola, J.-M., Basile, I., Bender, M., Chapellaz, J. Davis, M. E., Delaygue, G., Delmotte, M., Kotlyakov, V. M., Legrand, M., Lipenkov, V. Y., Lorius, C., Pepin, L., Ritz, C., Saltzman, E., Stievenard, M.: Climate and atmospheric history of the past 420000 years from the Vostok ice core, Antarctica, Nature, 399, 429-436, 1999.

Press, W. H., Teukolsky, S. A., Vetterling, W. T., and Flannery, B. P.: Numerical Recipes, 2nd ed., Cambridge University Press, Cambridge, 1992, $963 \mathrm{p}$.

Reeh, N.: Dating by ice flow modeling: a useful tool or an exercise in applied mathematics?, in: The environmental record in glaciers and ice sheet, edited by: Oeschger, H. and Langway, C. 
C., J. Wiley \& Sons, Chichester, 141-159, 1989.

Rotschky, G., Holmlund, P., Isaakson, E., Mulvaney, R., Oerter, H., Van den Broeke, M., and Winther, J.-G.: A new surface accumulation map for western Dronning Maud Land, Antarctica, from interpolation of point measurements, J. Glaciol., 53(182), 385398, 2007.

Ruth, U., Barnola, J.-M., Beer, J., Bigler, M., Blunier, T., Castellano, E., Fischer, H., Fundel, F., Huybrechts, P., Kaufmann, P., Kipfstuhl, S., Lambrecht, A., Morganti, A., Oerter, H., Parrenin, F., Rybak, O., Severi, M., Udisti, R., Wilhelms, F., and Wolff, E.: "EDML1": a chronology for the EPICA deep ice core from Dronning Maud Land, Antarctica, over the last 150000 years, Clim. Past, 3, 475-484, 2007, http://www.clim-past.net/3/475/2007/.

Rybak, O. and Huybrechts, P.: A comparison of Eulerian and Lagrangian methods for dating in numerical ice-sheet models, Ann. Glaciol., 37, 150-158, 2003.

Rybak, O., Huybrechts, P., Steinhage, D., and Pattyn F.: Dating and accumulation rate reconstruction along the Dome Fuji-Kohnen radio echo-sounding profile, Geophys. Res. Abstr., 7, 2005.

Savvin, A., Greve, R., Calov, R., Mügge, B., and Hutter, K.: Simulation of the Antarctic ice sheet with a three-dimensional polythermal ice-sheet model, in support of the EPICA project. II: Nested high-resolution treatment of Dronning Maud Land, Antarctica, Ann. Glaciol., 30, 69-75, 2006.

Severi, M., Becagli, S., Castellano, E., Morganti, A., Traversi, R., Udisti, R., Ruth, U., Fischer, H., Huybrechts, P., Wolff, E., Parrenin, F., Kaufmann, P., Lambert, F., and Steffensen, J. P.: Synchronisation of the EDML and EDC ice cores for the last $52 \mathrm{kyr}$ by volcanic signature matching, Clim. Past, 3, 367-374, 2007, http://www.clim-past.net/3/367/2007/.
Steinhage, D., Nixdorf, U., Meyer, U., and Miller, H.: Subglacial topography and internal structure of central and western Dronning Maud Land, Antarctica, determined from airborne radio echo sounding, J. Appl. Geophys., 47, 183-189, 2001.

Vimeux, F., Cuffey, K. M., and Jouzel., J.: New insights into Southern Hemisphere temperature changes from Vostok ice cores using deuterium excess correction, Earth. Planet. Sci. Lett., 203, 829-843, 2002

Waelbroeck, C., Labeyrie, L., Michel, E., Duplessy, J. C., McManus, J. F., Lambeck, K., Balbon, E., and Labracherie, M. Sea-level and deep water temperature changes derived from benthic foraminifera isotopic records, Quat. Sci. Rev., 21, 295-305, 2002.

Watanabe, O., Jouzel, J., Johnsen, S. J., Parrenin, F., Shoji, H., and Yoshida, N.: Homogenous climate variability across East Antarctica over the past three glacial cycles, Nature, 422, 509512, 2003.

Wesche, C., Eisen, O., Oerter, H., Schulte, D., and Steinhage, D.: Surface topography and ice flow in the vicinity of EDML deepdrilling site, J. Glaciol., 53(182), 442-448, 2007.

Wilhelms, F.: Explaining the dielectric properties of firn as a density-and-conductivity mixed permittivity (DECOMP), Geophys. Res. Lett., 32, L16501, doi:10.1029/2005GL022808, 2005. 